\title{
Expression of GLUT1 in Neoplastic Cells of Papillary Thyroid Cancer
}

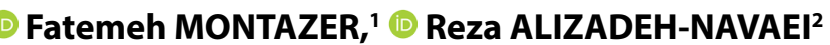

'Department of Pathology, Iran University of Medical Sciences, Tehran-Iran

${ }^{2}$ Gastrointestinal Cancer Research Center, Mazandaran University of Medical Sciences, Sari-Iran

\begin{abstract}
OBJECTIVE
Glucose transporter 1(GLUT1), as a member of the glucose transport facilitator family, has a role in some cancers. The present study aimed to investigate the expression level of GLUT1 in papillary thyroid cancer.

\section{METHODS}

This cross-sectional study was conducted in 2016 on tissue samples of patients, aged 18-60 years old, recently diagnosed with papillary thyroid cancer based on the WHO criteria. Anti-GLUT1 rat monoclonal antibody and LSAB Kit were used for immunohistochemistry. The intensity of marker expression was classified into three levels as follows: low, moderate and high. Other microscopic parameters, such as capsule invasion and tumor type, were also studied.
\end{abstract}

\section{RESULTS}

The present study was conducted in 67 patients (mean age: $37.2 \pm 10.3$ years old), including 37 (55.2\%) female patients. GLUT1 was expressed in all participants with papillary thyroid cancer, and high levels were observed in $64.2 \%$ of the patients. The elevated expression level was more frequent in men $(\mathrm{p}=0.04)$; however, no significant relationship was found between the expression level of GLUT1 and the pattern, capsule invasion, and lymph node metastases ( $p>0.05$ ). We observed no significant relationship between mean age and mean tumor size of patients with different expression levels of GLUT1.

\section{CONCLUSION}

GLUT1 was expressed at high levels in many patients with papillary thyroid cancer. However, there was no significant relationship between the expression of marker and tumor properties.

Keywords: Expression; GLUT1; papillary thyroid cancer.

Copyright $\odot$ 2019, Turkish Society for Radiation Oncology

\section{Introduction}

Thyroid cancer is the most common malignancy of the head and neck and endocrine system and accounts for more than 90\% of endocrinal neoplasia.[1] Evidence suggests a growing prevalence of thyroid cancer in some countries.[2-5] Many studies have attributed this to changes in lifestyle or environmental factors. [2]
At present, thyroid cancer is the six ${ }^{\text {th }}$ leading cancer in women and the second leading cancer in women younger than 40 years of age.[5] Different types of thyroid cancer include follicular thyroid cancer, papillary thyroid cancer, anaplastic thyroid cancer and medullary thyroid cancer.[6] Papillary thyroid cancer is the most common histologic subtype of thyroid cancer, accounting for $70 \%-90 \%$ of all thyroid 
cancers.[7] Various factors are used to predict the clinical outcome of papillary thyroid cancer, including age, size, capsular invasion, lymph node involvement, and extranodal and metastatic involvements. [8] These factors are suitable for selecting appropriate treatment strategies.[9] Moreover, recent attempts to enhance diagnostic accuracy and develop new prognostic criteria have proposed molecular and immunohistochemical markers. This is because, in addition to their diagnostic value, they can be used as a prognostic criterion.[10]

Studies suggest increased energy absorption from metabolism as an important characteristic of tumor cells.[11] This absorption is mediated by glucose transporters, whose expression and activity are regulated by oncogenes and growth factors. GLUT1, as a member of the glucose transport facilitator family with 13 members, is responsible for glucose uptake into human red blood cells.[12] GLUT1 is an energy-independent transport protein with a high affinity for glucose. It is highly expressed on endothelial cell surfaces at the blood-brain-barrier, allowing glucose entry into the brain,[13] on erythrocytes, [14] at the blood-ocular barrier,[15] and on the perineurium.[16] The elevated GLUT1 mRNA levels have been reported in the pancreas, colon, stomach, and esophagus cancers.[16, 17] Its expression is also elevated in the cancers of breast and cervix, renal cell carcinoma (RCC), squamous cell carcinomas of the head and neck, and carcinomas of other sites.[18-22] There are scant studies into the GLUT1 level in various thyroid malignancies.[23,24] To our knowledge, there is no study specific to its role and prognostic value in papillary cancer. Therefore, this study aimed to determine the expression level of GLUT1 in papillary thyroid cancer and its relationship with the disease prognosis.

\section{Materials and Methods}

This cross-sectional study was conducted in 2016 on tissue samples of patients, recently diagnosed with papillary thyroid cancer. The diagnosis was made based on the WHO criteria in the Department of Pathology at Mazandaran University of Medical Sciences. The inclusion criteria were being aged 18-60 years old, underwent thyroidectomy and lobectomy. Patients with incomplete tumor resection, preoperative radiotherapy, and tissue too scant for reliable assessment were excluded from this study. The sample size was estimated at least 64 , considering the confidence interval of $95 \%$ and GLUT1 expression of $60 \%$ in malignant thyroid masses, with an accuracy level of 0.12 . The formalin-fixed paraffin blocks of tumor samples were used to prepare the tissues for immunohistochemistry assessment. The slides were examined not only to confirm the tumor diagnosis but also to evaluate other microscopic parameters, such as capsular invasion and tumor type. For immunohistochemical staining, $5-\mu \mathrm{m}$ sections were prepared and placed on specific organo-silane-based glass slides. The slides were rinsed twice (each time for 10 minutes) in xylol to remove the remaining paraffin. They were then immersed in pure alcohol three times, and rinsed with tap water and then immediately with distilled water. Antigen was retrieved at $99^{\circ} \mathrm{C}$ for approximately 30 min in citrate buffer ( $\mathrm{pH} \mathrm{6).} \mathrm{After} \mathrm{reaching} \mathrm{the} \mathrm{room}$ temperature, the slides were immersed in $3 \%$ hydrogen peroxide for $10 \mathrm{~min}$. The slides were then incubated with the rat anti-GLUT1 monoclonal antibody 1:200 (DAKO Co) for $60 \mathrm{~min}$ at room temperature and then, rinsed with phosphate-buffered saline (PBS). Next, the samples were incubated using the LSAB Kit (DAKO Co) for $10 \mathrm{~min}$ at room temperature. Next, incubation was performed using a chromogen solution prepared with $\mathrm{DAB}$ for $10 \mathrm{~min}$ in a dark environment. After that, the samples were rinsed with tap water and then with distilled water.

Erythrocyte was used as a positive control. The negative control was carried out at the same time with the incubation of the sections. Positive parameters in the immunohistochemical marking of antigens included cases where the cells exhibited a brownish cytoplasm, regardless of the immune cell marker's stainability capacity. Images of five fields were randomly taken (400x magnification), using a camera with the highest imaging resolution. The intensity of marker expression was classified into three levels as follows: low, moderate, and high.[25] In addition to pathologic parameters, the age and sex of the patients were recorded. Data were analyzed using chi-square and ANOVA in SPSS. $\mathrm{P}<0.05$ was considered to be significant.

\section{Results}

The present study was conducted in 67 patients, including $30(44.8 \%)$ male and $37(55.2 \%)$ female patients. The mean age of the patients was $37.2 \pm 10.3$ years. The mean tumor size was $1.70 \pm 0.7 \mathrm{~cm}$. Other tumor properties are presented in Table 1.

Table 2 shows the relationship between GLUT1 and tumor properties. The findings showed that there was a significant relationship between GLUT1 
expression level and sex, and the higher expression level was more frequent in men $(\mathrm{p}=0.04)$, whereas there was no significant relationship between pattern, capsule invasion, and lymph node metastasis with the expression level ( $p>0.05)$. In addition, no significant relationship was found between mean age and tumor size of the patients with different GLUT1 expression levels (Table 3).

\begin{tabular}{|c|c|}
\hline Table 1 Th & \\
\hline Variable & n (\%) \\
\hline \multicolumn{2}{|l|}{ Pattern } \\
\hline Diffuse & $51(76.1)$ \\
\hline Negative & $16(23.9)$ \\
\hline \multicolumn{2}{|l|}{ Severity } \\
\hline Weak & $7(10.4)$ \\
\hline Moderate & $17(25.4)$ \\
\hline Strong & $43(64.2)$ \\
\hline \multicolumn{2}{|c|}{ Capsular invasion } \\
\hline No & $61(91)$ \\
\hline Yes & $6(9)$ \\
\hline \multicolumn{2}{|c|}{ Lymph node metastasis } \\
\hline No & $46(68.7)$ \\
\hline Yes & $21(31.3)$ \\
\hline
\end{tabular}

\begin{tabular}{|c|c|c|c|c|}
\hline & Weak & Moderate & Strong & p \\
\hline \multicolumn{5}{|l|}{ Pattern } \\
\hline Diffuse & $5(9.8)$ & $10(19.6)$ & $36(70.6)$ & 0.119 \\
\hline Negative & $2(12.5)$ & $7(43.8)$ & $7(43.8)$ & \\
\hline \multicolumn{5}{|l|}{ Sex } \\
\hline Male & - & $9(30)$ & $21(70)$ & 0.040 \\
\hline Female & $7(18.9)$ & $8(21.6)$ & $22(59.5)$ & \\
\hline \multicolumn{5}{|c|}{ Capsular invasion } \\
\hline No & $6(9.8)$ & $16(26.2)$ & $39(63.9)$ & 0.800 \\
\hline Yes & $1(16.7)$ & $1(16.7)$ & $4(66.7)$ & \\
\hline \multicolumn{5}{|l|}{$\begin{array}{l}\text { Lymph node } \\
\text { metastasis }\end{array}$} \\
\hline No & $5(10.9)$ & $14(30.4)$ & $27(58.7)$ & 0.334 \\
\hline Yes & $2(9.5)$ & $3(14.3)$ & $16(76.2)$ & \\
\hline
\end{tabular}

Table 3 Mean and standard deviation of age and thyroid tumor size in terms of GLUT1 expression level

\begin{tabular}{lcccc} 
& Weak & Moderate & Strong & p \\
\hline Age (mean \pm SD) & $38.2 \pm 11.6$ & $37.3 \pm 8.9$ & $37 \pm 10.8$ & 0.958 \\
Size (mean \pm SD) & $1.7 \pm 0.8$ & $1.5 \pm 0.7$ & $1.7 \pm 0.7$ & 0.570 \\
\hline
\end{tabular}

Hematoxylin-eosin and immunohistochemistry staining of papillary thyroid cancer are shown in Figures 1 and 2, respectively. Different immunohistochemistry staining of papillary thyroid cancer is presented in Figure 3.

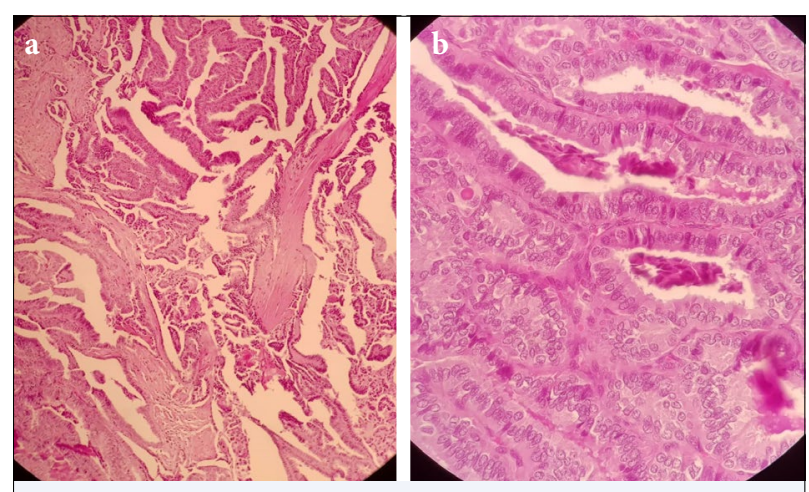

Fig. 1. Hematoxylin-eosin staining of papillary thyroid cancer for complex papillary structure with $100 \mathrm{x}$ (a) and nuclear features with $\times 400$ (b).

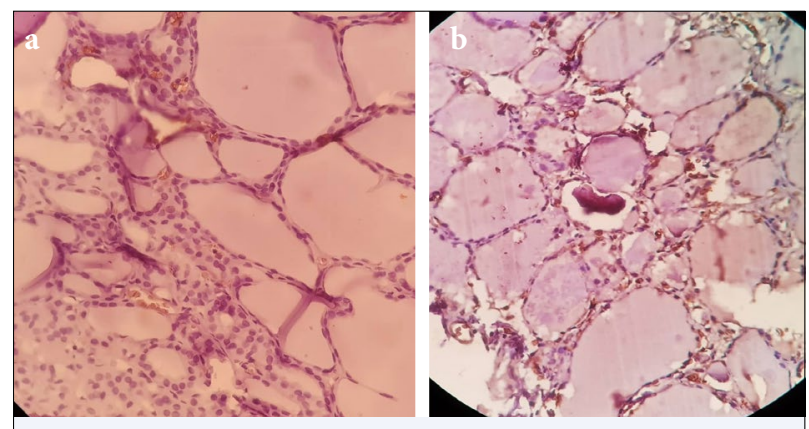

Fig. 2. Immunohistochemistry staining of papillary thyroid cancer with $\times 400$; No staining in thyroid hyperplastic nodule (a) and mild staining GLUT1 marker in hyperplastic nodule (b).
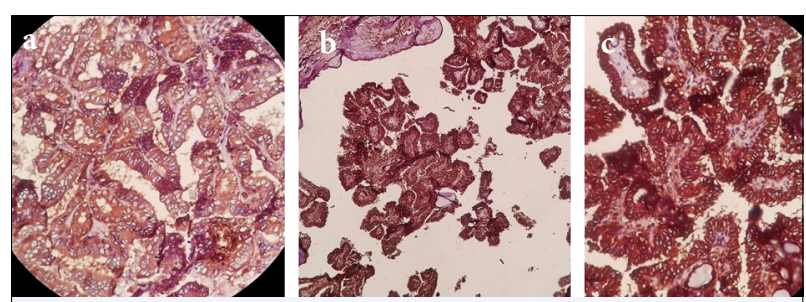

Fig. 3. Immunohistochemistry staining of papillary thyroid cancer; moderate staining GLUT1 marker with $\times 400$ (a), strong staining GLUT1 marker with $\times 100$ (b) and strong staining GLUT1 marker with $\times 400$ (c). 


\section{Discussion}

The present study showed elevated levels of GLUT1 expression in $64.2 \%$ of patients with papillary thyroid cancer. Haber et al.[26] reported GLUT1 expression in nine patients $(52.9 \%)$ out of a total of 17 patients with papillary thyroid cancer. Jóźwiak et al.[16] investigated 95 tumor cases, including anaplastic, follicular adenoma, papillary cancer, follicular cancer, and thyroid cancer with poor differentiation. Using immunohistochemistry, they found GLUT1 expression in $65 \%$ of cases with thyroid cancer. In addition to thyroid cancer, increased expression levels of GLUT1 were also observed in some other cancers. Reis et al. studied GLUT1 expression in 105 patients with uroepithelium tumors, using immunohistochemistry. They evaluated the stainability of GLUT1, using the standard immunoreactive score (IRS). They discovered that the GLUT1 expression level was significantly correlated with malignancy grading in noninvasive cancers; however, no significant relationship was reported between the GLUT1 expression level and the grade of invasive cancers. [6] A report on immunohistochemical patterns in rectal cancer found GLUT1 expression to be significantly correlated with poor prognosis. Moreover, increased GLUT1 level was seen to be correlated with metastasis. However, it was not believed to be correlated with prognostic factors.[17] An investigation of GLUT1 expression level and glucose metabolism into oral squamous cell carcinoma and their relationship with the disease prognosis showed higher survival rates in patients with lower GLUT1 levels.[5] Glucose is needed not only for the rapid production of ATP but also for biomass storage through the production of molecular precursors for nucleotides, cell membranes, and other cellular elements that have a role in cell division.[12] This marker has a role in glucose transport into the cell and displays high expression in papillary thyroid cancers; therefore, it could be used as a therapeutic marker. Similarly, a recent review showed that cancerous cell proliferation requires a high amount of glucose for energy generation, which is supplied from alternative pathways, so, GLU was recommended as a therapeutic marker.[27]

Current findings showed a significant relationship between GLUT1 expression level and sex. Indeed high expression level was more frequent in men $(p=0.04)$, whereas no significant relationship was observed between sex and the pattern, capsule involvement, and lymph node metastasis ( $>00.05)$. Jóźwiak et al.[16] found a significant correlation between the expression of GLUT1 and the proliferation of thyroid tumor samples.

A strength of this research was to investigate a specific type of thyroid tumor, namely papillary thyroid cancer. Limitations of this study include the lack of a control group. Further studies are recommended to investigate the effects of marker expression on patients' survival rates and prognosis through prospective research.

\section{Conclusion}

High expression levels of GLUT1 protein were observed in many patients with papillary thyroid cancer. However, there was no significant relationship between marker expression and tumor properties.

Peer-review: Externally peer-reviewed.

Conflict of Interest: There is no conflict of interest.

Financial Support: This research was supported by Mazandaran University of Medical Sciences (Project No: 2281).

Authorship contributions: Concept - F.M.; Design - F.M., R.A.N.; Supervision - F.M.; Materials - F.M.; Data collection \&/or processing - F.M.; Analysis and/or interpretation - R.A.N.; Literature search - R.A.N.; Writing - F.M., R.A.N.; Critical review - F.M., R.A.N.

\section{References}

1. Barzon L, Boscaro M, Pacenti M, Taccaliti A, Palù G. Evaluation of circulating thyroid-specific transcripts as markers of thyroid cancer relapse. Int J Cancer 2004;110(6):914-20.

2. Cho YA, Kong SY, Shin A, Lee J, Lee EK, Lee YJ, et al. Biomarkers of thyroid function and autoimmunity for predicting high-risk groups of thyroid cancer: a nested case-control study. BMC Cancer 2014;14(1):873.

3. Solomon B, Rischin D. Progress in Molecular Targeted Therapy for Thyroid Cancer: Vandetanib in Medullary Thyroid Cancer. J Clin Oncol 2012;30(2):119-21.

4. Kondo T, Ezzat S, Asa SL. Pathogenetic mechanisms in thyroid follicular-cell neoplasia. Nat Rev Cancer 2006;6(4):292-306.

5. Grogan RH, Mitmaker EJ, Clark OH. The Evolution of Biomarkers in Thyroid Cancer: From Mass Screening to a Personalized Biosignature. Cancers 2010;2:885-912.

6. Nozhat Z, Azizi F, Hedayati M. A Review on Molecular Biomarkers of Thyroid Carcinoma. J Mazandaran Univ Med Sci. 2015;25(125):154-70.

7. Dideban S, Abdollahi A, Meysamie A, Sedghi S, Shahriari M. Thyroid Papillary Microcarcinoma: Etiology, 
Clinical Manifestations,Diagnosis, Follow-up, Histopathology and Prognosis. Iran J Pathol 2016;11(1):1-19.

8. Romero-Rojas A, Cuervo-Martínez J, Osorio-Arango $\mathrm{K}$, Olaya N. Histological variants and prognostic factors of papillary thyroid carcinoma at the Colombian Instituto Nacional de Cancerología, 2006-2012. Biomedica 2015;35(3):429-36.

9. Ito Y, Miyauchi A, Kobayashi K, Kihara M, Miya A. Static and dynamic prognostic factors of papillary thyroid carcinoma. Endocr J 2014;61(12):1145-51.

10. Ruggeri RM, Campennì A, Baldari S, Trimarchi F, Trovato M. What is new on thyroid cancer biomarkers. Biomark Insights 2008;3:237-52.

11. Kunkel M, Reichert TE, Benz P, Lehr HA, Jeong JH, Wieand S, et al. Overexpression of Glut-1 and increased glucose metabolism in tumors are associated with a poor prognosis in patients with oral squamous cell carcinoma. Cancer 2003;97(4):1015-24.

12. Reis H, Tschirdewahn S, Szarvas T, Rübben H, Schmid KW, Grabellus F. Expression of GLUT1 is associated with increasing grade of malignancy in non-invasive and invasive urothelial carcinomas of the bladder. Oncol Lett 2011;2(6):1149-53.

13. Agus DB, Gambhir SS, Pardridge WM, Spielholz C, Baselga J, Vera JC, Golde DW. Vitamin C crosses the blood-brain barrier in the oxidized form through the glucose transporters. J Clin Invest 1997;100(11):2842-8.

14. Gould GW, Holman GD. The glucose transporter family: structure, function and tissue-specific expression. Biochem J 1993;295(Pt 2):32941.

15. Harik SI, Kalaria RN, Whitney PM, Andersson L, Lundahl P, Ledbetter SR, et al. Glucose transporters are abundant in cells with "occluding" junctions at the blood-eye barriers. Proc Natl Acad Sci USA 1990;87(11):4261-4.

16. Younes M, Lechago LV, Somoano JR, Mosharaf M, Lechago J. Wide expression of the human erythrocyte glucose transporter Glut1 in human cancers. Cancer Res 1996;56(5):1164-7.

17. Yamamoto T, Seino Y, Fukumoto H, Koh G, Yano H, Inagaki $\mathrm{N}$, et al. Over-expression of facilitative glucose transporter genes in human cancer. Biochem Biophys Res Commun.1990;170(1):223-30.

18. Brown RS, Wahl RL. Overexpression of Glut-1 glucose transporter in human breast cancer. An immunohistochemical study. Cancer 1993;72(10):297985.

19. Nagase Y, Takata K, Moriyama N, Aso Y, Murakami $\mathrm{T}$, Hirano $\mathrm{H}$. Immunohistochemical localization of glucose transporters in human renal cell carcinoma. J Urol 1995;153(3 Pt 1):798-801.

20. Mellanen P, Minn H, Grénman R, Härkönen P. Expression of glucose transporters in head-and-neck tumors. Int J Cancer 1994;56(5):622-9.

21. Cooper R, Sarioğlu S, Sökmen S, Füzün M, Küpelioğlu A, Valentine H, et al. Glucose transporter-1 (GLUT$1)$ : a potential marker of prognosis in rectal carcinoma?. Br J Cancer 2003;89(5):870-6.

22. Airley R, Loncaster J, Davidson S, Bromley M, Roberts S, Patterson A, et al. Glucose transporter glut-1 expression correlates with tumor hypoxia and predicts metastasis-free survival in advanced carcinoma of the cervix. Clin Cancer Res 2001;7(4):928-34.

23. Jóźwiak P, Krześlak A, Bryś M, Lipińska A. Glucosedependent glucose transporter 1 expression and its impact on viability of thyroid cancer cells. Oncol Rep 2015;33(2):913-20.

24. Jóźwiak P, Krześlak A, Pomorski L, Lipińska A. Expression of hypoxia-related glucose transporters GLUT1 and GLUT3 in benign, malignant and non-neoplastic thyroid lesions. Mol Med Rep 2012;6(3):601-6.

25. Kang SS, Chun YK, Hur MH, Lee HK, Kim YJ, Hong $\mathrm{SR}$, et al. Clinical significance of glucose transporter 1 (GLUT1) expression in human breast carcinoma. Jpn J Cancer Res 2002;93(10):1123-8.

26. Haber RS, Weiser KR, Pritsker A, Reder I, Burstein DE. GLUT1 glucose transporter expression in benign and malignant thyroid nodules. Thyroid 1997;7(3):363-7.

27. Ciavardelli D, Bellomo M, Consalvo A, Crescimanno C, Vella V. Metabolic Alterations of Thyroid Cancer as Potential Therapeutic Targets. Biomed Res Int 2017;2017:2545031 